\title{
Article
}

\section{A thorax marker set model to analyse the kinematics of walking without the need to place markers on the back}

Orantes-Gonzalez, Eva, Heredia-Jimenez, Jose, Chohan, Ambreen and Richards, James

Available at https://clok.uclan.ac.uk/35458/

Orantes-Gonzalez, Eva, Heredia-Jimenez, Jose, Chohan, Ambreen orcid iconORCID: 0000-0003-0544-7832 and Richards, James orcid iconORCID: 0000-0002-4004-3115 (2021) A thorax marker set model to analyse the kinematics of walking without the need to place markers on the back. Journal Of Biomechanical Engineering, 143 (4). ISSN $0148-0731$

It is advisable to refer to the publisher's version if you intend to cite from the work. http://dx.doi.org/10.1115/1.4049160

For more information about UCLan's research in this area go to http://www.uclan.ac.uk/researchgroups/ and search for <name of research Group>.

For information about Research generally at UCLan please go to http://www.uclan.ac.uk/research/

All outputs in CLoK are protected by Intellectual Property Rights law, including Copyright law. Copyright, IPR and Moral Rights for the works on this site are retained by the individual authors and/or other copyright owners. Terms and conditions for use of this material are defined in the policies page.

\section{CLoK}

Central Lancashire online Knowledge www.clok.uclan.ac.uk

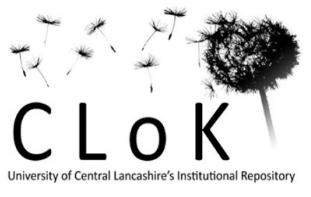




\title{
A thorax marker set model to analyse the kinematics of walking without the need to place markers on the back
}

\section{Eva Orantes-Gonzalez ${ }^{1,2}$, Jose Heredia-Jimenez ${ }^{1,2}$, Ambreen Chohan ${ }^{3}$ and Jim D Richards $\mathbf{s}^{3}$}

${ }^{1}$ Faculty of Education, Economy and Technology. Department of Physical Education and Sport. University of Granada. Ceuta, Spain.

${ }^{2}$ Human Behavior and Motion Analysis Lab (Hubema Lab). University of Granada. Ceuta, Spain.

${ }^{3}$ Allied Health Research unit, University of Central Lancashire, UK

\begin{abstract}
Background: Previous thorax models have been proposed for gait analysis, however these require markers to be placed on the back. This presents a limitation in the kinematic analysis of the thorax under load carriage conditions.

Research question: This study evaluated the validity and reliability of a thorax marker set that does not require markers to be placed on the back (HubemaLab model) when compared to 3 previously published marker set models that require markers to be placed on the back.

Methods: Seventeen young adults were evaluated while walking at their self-selected speed. A 12 camera motion capture system was used to acquire the marker position data which was then processed using the respective models using Visual 3D. The level of agreement for the flexion/extension peak, right/left lateral peak and right/left rotation peak of the thorax angle and angular velocity; together with the range of motion and
\end{abstract}


thorax angular velocities in the three planes was found between each thorax marker set, while the reliability was measured using the intraclass correlation coefficient.

Results: The ICC results for the thorax angle ROM and the range of thorax angular velocity between the HubemaLab model and the other models showed excellent to good reliability in all three planes. While the ICCs for the peak flexion/extension, peak right/left lateral flexion and peak right/left rotation showed excellent to moderate reliability in all three planes.

Conclusion: The new model could be potentially valuable for kinematic gait analysis under load carriage conditions which obscure markers placed on the back.

Keywords: motion analysis, spine, gait, biomechanics, validity.

\section{INTRODUCTION}

During three-dimensional kinematic analysis, markers can become occluded by an individual's body position or clothing (1). In addition, for gait analysis under conditions where participants have to carry an object or equipment on the back, i.e. a school or military backpack, the occlusion of the reflective markers on the back and pelvis are inevitable.

Anatomical landmark recommendations by the International Society of Biomechanics (ISB), show the thorax to be defined by the seventh cervical vertebra (C7), eighth thoracic vertebra (T8), deepest point of incisura jugularis (IJ), most caudal point of the sternum (PX); and additional clavicle markers, such us acromioclavicular markers (AC) (2). Other marker set models have been proposed for gait analysis, however all of these recommend the placement of markers on the back. In this way, the model proposed by Rab et al., (3), recommended the placement of the thorax markers on IJ, C7 and AC. Whereas Armand et al., (4) reported that the optimal and minimal marker set for the thorax should contain IJ, second thoracic vertebra (T2) and tenth thoracic vertebra (T10) or T8. However, it is possible to divide the thorax into different segments. Previous 
work has reported the use of a 7-segment spinal model which included; sacral, lower lumbar, upper lumbar, lower thoracic, mid-lower thoracic, mid-upper thoracic and upper thoracic segments (5). This reported that the degree of segmentation of the kinematic model of the spine affected the total trunk motion measured during multiplanar movements. In addition, a 3D marker cluster based kinematic model was validated to assess regional movements of the spine, this divided the spine into lumbar, upper thoracic and lower thoracic segments (6).

All of the previous thorax marker set models proposed for kinematic analysis showed difficulties when analyzing gait during load carriage with bags, backpacks or similar equipment due to the issues of placement of markers on the posterior and anterior upper body. Therefore, to reduce the occlusion of the thorax markers, different potential solutions have been identified. Previous studies have analysed the influence of carrying different backpack loads on trunk kinematics using a "dummy" backpack instead of using a normal designed backpack, which has allowed the visibility of the markers on the thorax (7-9). For situations where the placement of the thorax markers was difficult, the use of an upper-back marker cluster that allowed the analysis of the thorax motion has been validated (10), although the thorax model still required the placement of two rigid clusters on the back, located over $\mathrm{C} 7$ and the sacrum.

Other solutions to the occlusion of markers during gait while carrying a backpack have included the placement of marker clusters to account for extrapolation of markers hidden by the backpack (11). However, detailed information on the location or methods of calculating segment kinematics were not reported. Other studies have also removed the posterior trunk and pelvis markers while walking carrying a backpack, in addition to the acromion markers after the static calibration to avoid the interference with the backpack straps, however the model is yet to be validated (12).

A thorax marker set model without the need to place markers on the posterior aspect of the thorax could be potentially valuable for kinematic gait analysis under load carriage conditions, where individuals have to carry a load on the back or while wearing specialist equipment such as backpacks. The purpose of this current study was to describe and validate a possible thorax marker set for 3D motion analysis that does not 
require the placement of markers on the spine, therefore allowing the analysis of the thorax during gait in such conditions.

\section{METHODS}

\subsection{Participants}

Seventeen healthy young adults, 4 males and 13 females participated in this study (mean \pm SD: mass $60.1 \pm 13.9 \mathrm{~kg}$, height $1.67 \pm 0.08 \mathrm{~m}$, age $23.1 \pm 9$ years). All of the participants had a body mass index (BMI) between 18.5 to $25 \mathrm{~kg} / \mathrm{m}^{2}$. Exclusion criteria included; suffering from musculoskeletal injuries or disorders that could affect walking ability. All participants volunteered for the study and completed an informed consent form in line with the Universities Ethics procedures (Ref: 137/CEIH/2016).

\subsection{Protocol}

Retro-reflective markers $(\varnothing 14 \mathrm{~mm})$ were placed with double-sided tape over the individuals' skin following the recommendation of Van Sint Jan (13). The 3D marker positions were acquired using a 12-camera motion analysis system (Qualisys AB, Göteborg, Sweden), 6 Oqus 500 and 6 Oqus 510, sampling at $100 \mathrm{~Hz}$.

A static calibration trial was recorded for 1 second for each participant during standing in an anatomically neutral pose (14), although calibration is not necessary for the ISB model. Each participant completed a familiarization phase where they walked with the markers positioned for 5 minutes along a 15 meter level walkway. Participants walked barefoot for at least three trials at a self-selected speed. The female participants wore a sport bra that allowed the placement of the chest reflective markers.

\subsection{Marker set models}

Anatomical markers were placed at anatomically relevant locations and were used to define and/or track the segments, while the tracking markers were placed at convenient locations and were only used for tracking the segments (Table 1). For the pelvis model, markers were placed on the right and left posterior superior iliac spine (PSIS) and anterior superior iliac spine (ASIS), following the model proposed by Bell et al., $(15,16)$ 
(Table 1). The foot markers were placed on the right and left sides of the dorsal aspect of the first metatarsal head (FM1), the head of the second and fifth metatarsal (FM2 and FM5) and the posterior surface of the calcaneus (FCC) (Table 1). The foot was subsequently used to determine gait events.

\section{"INSERT TABLE 1 AROUND HERE"}

Different marker set configurations were tested with respect to the thorax (Table 1). These included the Rab model (3), the ISB model (17) and an upper and lower thoracic model (5). All of the models were compared to the HubemaLab model, which did not include markers on the back, and has been used in previous gait studies to explore different bag carriage conditions $(12,18)$. The local reference frame was aligned with the global reference frame for all models. A total of 34 markers were placed on each subject. Although this does not cover all available models, this aimed to explore if a marker set that can be used when wearing a backpack is comparable to 3 commonly used models in such assessments. The sternum xiphisternal (SXS) and the right and left costal cartilage of the $7^{\text {th }}$ ribs (RM7 and LM7) markers proposed for the trunk segment are close to the breasts, however these have been shown to be effectively tracked in women wearing a sport bra while running (19). The acromioclavicular markers were necessary to define the distal point to compute the trunk segments in the ISB, Rab and HubemaLab models. Although in the HubemaLab model, the acromioclavicular markers together with the PSIS markers, could be removed after the static calibration.

\subsection{Data analysis}

Qualisys Track Manager software (QTM version 2.18, Qualisys, Sweden) was used to record data. Then, data were processed using Visual 3D software v.6.0 (C-Motion, USA). For the marker trajectories of all trials, a maximum gap interpolation of 10 frames using a $3^{\text {rd }}$ order polynomial with a $6 \mathrm{~Hz}$ lowpass second order Butterworth filter was applied. The XYZ directions were defined as; $\mathrm{x}$-axis in the mediolateral direction, $\mathrm{y}$-axis in the anterior/posterior direction and the z-axis as the axial movement. An XYZ Cardan rotation sequence was defined as rotation in the $\mathrm{X}$-axis (flexion-extension), $\mathrm{Y}$ axis (lateral side bending) and Z-axis (axial rotation), with the thorax segment of each 
marker set being computed relative to the pelvis segment. At least, 9 left strides and 9 right strides in total were captured and averaged.

A coordinate-based algorithm (20) was used to identify the heel-strike event that was then used to obtain the gait cycle duration. Kinematic variables were normalized from 0 to $100 \%$ of the gait cycle. The variables included range of motion (ROM) (max-min) and range of thorax angular velocity in the three planes, together with the peaks of the thorax angle and thorax angular velocity (flexion/extension peak, right/left flexion peak and right/left rotation peak). To assess the level of agreement between the models for each variable, the MedCalc software v.18.6 (MedCalc, Ostend, Belgium) was used to perform Bland-Altman tests. The mean difference and 95\% limits of agreement between each comparison were calculated.

Then, SPSS software v.24 (SPSS Inc., Chicago, IL) was used to assess the reliability using the intraclass correlation coefficient (ICC) of 2-way mixed-effects model (absolute agreement). The absolute agreement determines whether using the different marker sets provide the same flexion/extension peak, right/left flexion peak and right/left rotation peak in the thorax angle and the thorax angular velocity; and also, in the thorax angle ROM and thorax angular velocity in the same subject. An ICC lower than 0.5 was considered as "poor reliability", between 0.5-0.75 as "moderate reliability", between $0.75-0.9$ "good reliability", and higher than 0.9 as "excellent reliability" (21).

\section{RESULTS}

The thorax angle and the thorax angular velocity waveforms across the gait cycle in the different models tested are represented in Figure 1.

\section{"INSERT FIGURE 1 AROUND HERE"}

The averages and standard deviations from the ROM of the angle and the range of thorax angular velocity while walking are displayed in Table 2 . In addition, the mean 
difference and the 95\% limits of agreement (upper and lower bound) between each marker model comparison are reported in Table 2.

\section{"INSERT TABLE 2 AROUND HERE"}

The ICC absolute agreement results for the thorax angle ROM and the range of thorax angular velocity between the HubemaLab model and the other models showed excellent to good reliability in all three planes (Table 3). With respect to the ICCs for the flexion/extension peak, right/left lateral flexion peak and right/left rotation peak for the thorax angle and the thorax angular velocity, the HubemaLab model showed excellent to moderate reliability in all three planes. Furthermore, excellent agreement was found between the HubemaLab model and the different thorax models during walking for the peak thorax angular velocities in all three planes (Table 4).

\section{"INSER TABLE 3 AROUND HERE"}

In addition, the Bland-Altman plots obtained between the HubemaLab model and the other models tested relative to thorax angle ROM and the range of angular velocity are displayed in supplementary material (Figure 2 and Figure 3, respectively). The BlandAltman plots presented showed narrow limits, especially in the analysis of thorax angle ROM comparisons, where the different models were essentially equivalent.

\section{"INSERT TABLE 4 AROUND HERE"}

\section{DISCUSSION}

In this study, the accuracy of the HubemaLab model has been tested and found suitable for the assessment of 3D kinematic analysis of the thorax while walking. For the analysis of the trunk kinematics while carrying a backpack, the occlusion of the back markers has been seen as a limiting factor for such analysis and has therefore needed the use of dummy backpacks, instead of the use of unmodified backpacks, in order to avoid the occlusion of the thorax markers (7-9). The HubemaLab model could therefore be used in these situations, removing the need to place markers on the back, and also allowing the removal of the acromion and PSIS markers after the static calibration. 
In the kinematic analysis of the thorax, the HubemaLab model resulted in excellent reliability and consistency compared to the ISB and Rab thorax models; even in the analysis of the peak values of the thorax angular velocity. When using motion capture to measure thorax motion, this model allows the possibility to dispense with the need to place an upper-back marker cluster (10) or extrapolate the markers hidden by the backpack (11), which has been previously suggested for kinematic analysis whilst walking under backpack conditions.

The proposed marker set model showed high agreement in the thorax angle ROM. In the study by Preuss and Popovic (5), where the axial rotation and side-bending of the trunk during sitting were analysed, the results indicated that the degree of segmentation of the kinematic model of the spine seemed to affect the total trunk motion measured during multi-planar movements. In this study, the upper and lower thoracic segments followed very similar patterns of movement during walking with similar thorax ROM in all three planes. However, the range of angular velocity in the transverse plane showed greater differences in the lower and upper thoracic segments, with the HubemaLab single segment model showing less range of angular velocity than the multi-segment thorax model. This indicates that a single segment analysis may not show the same sensitivity to specific intersegmental kinematics.

Although a previous study validated an alternative marker set model to reliably measure trunk and pelvis motion under carriage conditions (10), this still required the need to place markers on the acromions, backpack and cervical segment. The new back markerless model demonstrated validity in the measurement of the amount of thorax movement and angular velocity compared to previous one segment thorax models while walking. However, although the HubemaLab model has a good ICC compared to upper and lower thorax models, caution should be used when applying the results of the current study to multi-segment thorax comparisons, which is highlighted by the analysis of the range of angular velocity, where the mean difference was too great to be considered a good agreement.

The limitations of this study included, only young adults were tested with a range of BMI between 18.5 to $25 \mathrm{~kg} / \mathrm{m}^{2}$. Therefore, possible variations in the accuracy due to 
higher BMI values needs to be further explored. In addition, the marker on the chest could be affected by additional soft or adipose tissue, that could increase movement artefacts in the marker positions.

Although the ROM of the thorax angle showed good agreement between models in the sagittal plane, and in most of the peak analysis of thorax angle and thorax angular velocity, measures of discrete points did show an offset due to the differences in the anatomical segment orientations. The HubemaLab model showed an overestimation of the thorax angle compared to upper and ISB models, so if "absolute angle values" are required then differences can be observed between the models which should be used with caution. For this reason, the authors advise the consideration of ROM, or measures of excursion, when comparing data from different models, in particular when measuring values in the sagittal plane. Further studies should test the model during sporting tasks and activities of daily living, in addition comparisons between time series data curves could be performed to identify possible differences during the whole gait cycle.

\section{CONCLUSIONS}

This study developed a new back markerless model that could be potentially valuable for kinematic gait analysis under conditions where individuals have to carry a posterior load or other spinal marker obscuring scenarios. The 3D movement analysis of the thorax compared well to previously published models, including one segment and multi-segment thorax models. Although in the analysis of the range of angular velocity, the comparison between the HubemaLab model and the multi-segment thorax model should be treated with caution.

\section{REFERENCES}

[1] Piazza, T.; Lundström, J.; Kunz, A.; Fjeld, M. Predicting missing markers in real-time optical motion capture, in Model. Physiol. Hum., Springer, Berlin, 2009: 125-136. doi:10.1007/978-3-642-10470-1_11.

[2] Wu, G.; Van Der Helm, F.C.T.; Veeger, H.E.J.; Makhsous, M.; Van Roy, P.; 
Anglin, C.; Nagels, J.; Karduna, A.R.; McQuade, K.; Wang, X.; Werner, F.W.; Buchholz, B. ISB recommendation on definitions of joint coordinate systems of various joints for the reporting of human joint motion - Part II: Shoulder, elbow, wrist and hand. $J$ Biomech 2005, 38, 981-992. doi:10.1016/j.jbiomech.2004.05.042.

[3] Rab, G.; Petuskey, K.; Bagley, A. A method for determination of upper extremity kinematics. Gait Posture 2002, 15, 113-119. doi:10.1016/S0966-6362(01)001552.

[4] Armand, S.; Sangeux, M.; Baker, R. Optimal markers' placement on the thorax for clinical gait analysis. Gait Posture 2014, 39, 147-153. doi:10.1016/j.gaitpost.2013.06.016.

[5] Preuss, R.A.; Popovic, M.R. Three-dimensional spine kinematics during multidirectional, target-directed trunk movement in sitting. J Electromyogr Kinesiol 2010, 20, 823-832. doi:10.1016/j.jelekin.2009.07.005.

[6] R. Needham, R.; Naemi, Healy, A.; Chockalingam, N. Multi-segment kinematic model to assess three-dimensional movement of the spine and back during gait. Prosthet Orthot Int 2016, 40, 624-635. doi:10.1177/0309364615579319.

[7] Chow, D.H.K.; Wang, C.; Pope, M.H. Effects of backpack carriage on lumbopelvic control: A dynamical systems analysis. Int J Ind Ergon 2014, 44, 493-498. doi:10.1016/j.ergon.2014.04.002.

[8] LaFiandra, M.; Wagenaar, R.C.; Holt, K.G.; Obusek, J.P. How do load carriage and walking speed influence trunk coordination and stride parameters? $J$ Biomech 2003, 36, 87-95. doi:http://dx.doi.org/10.1016/S0021-9290(02)002439.

[9] Singh, T.; Koh, M. Effects of backpack load position on spatiotemporal parameters and trunk forward lean. Gait Posture 2009, 29, 49-53. doi:10.1016/j.gaitpost.2008.06.006.

[10] Lenton, G.K.; Doyle, T.L.A.; Saxby, D.J.; Lloyd, D.G. An alternative wholebody marker set to accurately and reliably quantify joint kinematics during load carriage. Gait Posture. 2017, 54, 318-324. doi:10.1016/j.gaitpost.2017.04.002.

[11] Devroey, C.; Jonkers, I.; de Becker, A.; Lenaerts, G.; Spaepen, A. Evaluation of the effect of backpack load and position during standing and walking using biomechanical, physiological and subjective measures. Ergonomics 2007, 50, 728-742. doi:10.1080/00140130701194850. 
[12] Orantes-Gonzalez, E.; Heredia-Jimenez, J.; Beneck, G.J. Children require less gait kinematic adaptations to pull a trolley than to carry a backpack. Gait Posture 2017, 52, 189-193. doi:10.1016/j.gaitpost.2016.11.041.

[13] Van Sint Jan, S. Color Atlas of Skeletal Landmark Definitions: Guidelines for Reproducible Manual and Virtual Palpations, Elsevier Health Sciences, 2007.

[14] Cappozzo, A.; Catani, F.; Della Croce, U.; Leardini, A. Position and orientation in space of bones during movement: anatomical frame definition and determination. Clin Biomech 1995, 10, 171-178. doi:10.1016/02680033(95)91394-T.

[15] Bell, A.L.; Brand, R.A.; Pedersen, D.R. Prediction of hip joint centre location from external landmarks. Hum Mov Sci 1898, 8, 3-16. doi:10.1016/01679457(89)90020-1.

[16] Bell, A.L.; Pedersen, D.R.; Brand, R.A. A comparison of the accuracy of several hip center location prediction methods. $J$ Biomech 1990, 23, 617-21. doi:10.1016/0021-9290(90)90054-7.

[17] Wu, G.; Siegler, S.; Allard, P.; Kirtley, C.; Leardini, A.; Rosenbaum, D.; Whittle, M.; Lima, D.D.D.; Cristofolini, L.; Witte, H.; Schmid, O.; Stokes, I. ISB recommendation on definitions of joint coordinate system of various joints for the reporting of human joint motion-part I: ankle, hip, and spine. J Biomech 2002, 35, 543-548. doi:10.1016/S0021-9290(01)00222-6.

[18] Orantes-Gonzalez, E.; Heredia-Jimenez, J. Pulling a school trolley: A good kinematic option for children. Gait Posture 2017, 53, 61-66. doi:10.1016/j.gaitpost.2017.01.012.

[19] Mills, C.; Loveridge, A.; Milligan, A.; Scurr, J. Trunk marker sets and the subsequent calculation of trunk and breast kinematics during treadmill running. Textile Research J 2015, 86, 1128-1136. doi.org/10.1177/0040517515609257.

[20] Zeni, J.A.; Richards, J.A.; Higginson, J.S. Two simple methods for determining gait events during treadmill and overground walking using kinematic data. Gait Posture 2008, 27, 710-714. doi:10.1016/j.gaitpost.2007.07.007.

[21] Portney, L.; Watkins, M. Foundations of Clinical Research: Applications to Practice (3rd Edition), Prentice Hall, New Yersey, 2015. doi:10.1331/JAPhA.2011.10034. 


\section{ACKNOWLEDGEMENTS}

The work of Orantes-González, E was supported by the Ministry of Education, Culture and Sports of Spain (ref. FPU13/00162, EST15/00019). In addition to, the Mobility Program of the University of Granada supported the work of Heredia-Jimenez, J and Orantes-Gonzalez, E. 


\section{TABLES}

Table 1. Marker locations and landmark definition for the conventional thorax models tested and the back markerless proposed.

\begin{tabular}{|c|c|c|}
\hline Marker models & Markers description & Tracking markers \\
\hline $\begin{array}{l}\text { RAB } \\
\text { MODEL }\end{array}$ & $\begin{array}{l}\text { AC: Acromioclavicular marker } \\
\text { SJN: Sternum jugular notch } \\
\text { C7: Cervical Vertebrae } 7 \\
\text { PSIS: Posterior Superior Iliac Spine } \\
\text { ASIS: Anterior superior iliac spine } \\
\text { ILIAC (Vitual Markers): lateral surface of the ilium at } 1 / 2 \\
\text { between the lateral point on sup. tubercle of the iliac crest and the } \\
\text { origin of gluteus medius post. fibers } \\
\text { SACR (Virtual Marker): sacrum }\end{array}$ & C7, LAC, RAC, SJN \\
\hline ISB MODEL & $\begin{array}{l}\text { AC: Acromioclavicular marker } \\
\text { SJN: Sternum jugular notch } \\
\text { SXS: Sternum Xiphisternal } \\
\text { C7: Cervical Vertebrae } 7 \\
\text { T1: Thoracic Vertebrae } 1 \\
\text { MAI: } 1 / 2 \text { between inferior angles of most caudal points } \\
\text { of scapula } \\
\text { L1, L2, L3: Lumbar Vertebrae } 1,2,3\end{array}$ & C7, SJN, SXS, MAI \\
\hline $\begin{array}{l}\text { UPPER } \\
\text { THORACIC } \\
\text { MODEL }\end{array}$ & $\begin{array}{l}\text { C7: Cervical Vertebrae } 7 \\
\text { C7R: Marker at C7 level spaced } 1 \mathrm{~cm} \text { to the right. } \\
\text { C7L: Marker at C7 level spaced } 1 \mathrm{~cm} \text { to the left. } \\
\text { T1R: Marker at T1 level spaced } 1 \mathrm{~cm} \text { to the right. } \\
\text { T1L: Marker at T1 level spaced } 1 \mathrm{~cm} \text { to the left. }\end{array}$ & T1, C7, C7L, C7R \\
\hline $\begin{array}{l}\text { LOWER } \\
\text { THORACIC } \\
\text { MODEL }\end{array}$ & $\begin{array}{l}\text { T7: Thoracic Vertebrae } 7 \\
\text { T7R: Marker at T7 level spaced } 1 \mathrm{~cm} \text { to the right. } \\
\text { T7L: Marker at T7 level spaced } 1 \mathrm{~cm} \text { to the left. } \\
\text { T8R: Marker at T8 level spaced } 1 \mathrm{~cm} \text { to the right. } \\
\text { T8L: Marker at T8 level spaced } 1 \mathrm{~cm} \text { to the left. }\end{array}$ & T7, T8, C7L, C7R \\
\hline $\begin{array}{l}\text { HUBEMALAB } \\
\text { MODEL }\end{array}$ & $\begin{array}{l}\text { AC: Acromioclavicular marker } \\
\text { SJN: Sternum jugular notch } \\
\text { SXS: Sternum Xiphisternal } \\
\text { M7: Costal cartilage of the } 7^{\text {th }} \text { ribs } \\
\text { ASIS: Anterior superior iliac spine } \\
\text { PSIS: Posterior Superior Iliac Spine } \\
\text { ILIAC (virtual markers) }\end{array}$ & RM7, LM7, SJN, SXS \\
\hline
\end{tabular}


Table 2. Mean (standard deviation), mean difference and upper and lower $95 \%$ limits of agreement (95\% LOA) values between each thorax model and HubemaLab model.

\begin{tabular}{|c|c|c|c|c|c|c|c|c|}
\hline & \multicolumn{4}{|c|}{ ROM Thorax Angle } & \multicolumn{4}{|c|}{ Range of Angular Velocity } \\
\hline & \multirow{2}{*}{$\begin{array}{c}\text { Mean (SD) } \\
\text { (Degrees) }\end{array}$} & \multirow{2}{*}{$\begin{array}{c}\text { Mean } \\
\text { difference }\end{array}$} & \multicolumn{2}{|c|}{$95 \%$ LOA } & \multirow[t]{2}{*}{$\begin{array}{l}\text { Mean (SD) } \\
\text { (Degrees/second) }\end{array}$} & \multirow{2}{*}{$\begin{array}{l}\text { Mean } \\
\text { difference }\end{array}$} & \multicolumn{2}{|c|}{$95 \%$ LOA } \\
\hline & & & Lower & Upper & & & Lower & Upper \\
\hline \multicolumn{9}{|l|}{ Sagittal plane } \\
\hline HubemaLab & $3.9(1.7)$ & & & & $61.8(30.0)$ & & & \\
\hline ISB & $3.9(1.8)$ & -0.06 & -0.25 & 0.13 & $60.5(32.0)$ & 1.32 & -1.25 & 3.88 \\
\hline Lower Thoracic & $4.7(1.9)$ & -0.91 & -1.45 & -0.37 & $63.3(27.7)$ & -1.49 & -6.94 & 3.96 \\
\hline Rab & $4.1(1.9)$ & -0.33 & -0.71 & 0.05 & $61.4(33.8)$ & 0.44 & -3.33 & 4.21 \\
\hline Upper Thoracic & $4.9(1.9)$ & -1.23 & -1.95 & -0.50 & $66.2(32.4)$ & -4.34 & -10.09 & 1.41 \\
\hline \multicolumn{9}{|l|}{ Frontal plane } \\
\hline HubemaLab & $2.4(1.2)$ & & & & $35.5(17.3)$ & & & \\
\hline ISB & $2.7(0.9)$ & -0.56 & -1.16 & 0.04 & $37.1(16.1)$ & -1.60 & -2.94 & -0.26 \\
\hline Lower Thoracic & $2.5(0.9)$ & -0.17 & -0.38 & 0.04 & $36.1(13.9)$ & -0.67 & -3.52 & 2.19 \\
\hline Rab & $2.5(1.3)$ & -0.13 & -0.31 & 0.05 & $36.9(15.2)$ & -1.37 & -3.83 & 1.09 \\
\hline Upper Thoracic & $2.7(1.4)$ & -0.55 & -1.13 & 0.03 & $36.3(14.8)$ & -0.81 & -3.29 & 1.69 \\
\hline \multicolumn{9}{|l|}{ Transverse plane } \\
\hline HubemaLab & $2.4(0.9)$ & & & & $36.6(12.3)$ & & & \\
\hline ISB & $2.5(0.9)$ & -0.01 & -0.49 & 0.47 & $38.5(14.5)$ & -1.89 & -5.57 & 1.79 \\
\hline Lower Thoracic & $2.5(0.9)$ & -0.38 & -0.70 & -0.06 & $41.3(16.0)$ & -4.70 & -8.87 & -0.53 \\
\hline Rab & $2.9(1.1)$ & -0.64 & -1.12 & -0.17 & $39.9(13.7)$ & -3.31 & -6.97 & 0.35 \\
\hline Upper Thoracic & $2.8(0.9)$ & -0.46 & -0.77 & -0.15 & $43.5(15.0)$ & -6.85 & -10.61 & -3.10 \\
\hline
\end{tabular}


Table 3. Intraclass correlation coefficient (ICC absolute agreement, 95\% confident interval (lower and upper bounds) of the different thorax models analyzed compared to the HubemaLab thorax model while walking.

\begin{tabular}{|c|c|c|c|c|c|c|}
\hline & \multicolumn{3}{|c|}{ ROM Thorax Angle } & \multicolumn{3}{|c|}{ Range of Angular Velocity } \\
\hline & \multirow[b]{2}{*}{ ICC } & \multicolumn{2}{|c|}{$95 \% \mathrm{CI}$} & \multirow[b]{2}{*}{ ICC } & \multicolumn{2}{|c|}{$95 \% \mathrm{CI}$} \\
\hline & & Lower & Upper & & Lower & Upper \\
\hline \multicolumn{7}{|l|}{ Sagittal plane } \\
\hline ISB & 0.99 & 0.97 & 0.99 & 0.99 & 0.98 & 0.99 \\
\hline Lower Thoracic & 0.88 & 0.42 & 0.96 & 0.97 & 0.91 & 0.99 \\
\hline $\mathrm{Rab}$ & 0.96 & 0.88 & 0.99 & 0.99 & 0.97 & 0.99 \\
\hline Upper Thoracic & 0.80 & 0.20 & 0.94 & 0.97 & 0.90 & 0.99 \\
\hline \multicolumn{7}{|l|}{ Frontal plane } \\
\hline ISB & 0.97 & 0.90 & 0.99 & 0.99 & 0.97 & 0.99 \\
\hline Lower Thoracic & 0.99 & 0.99 & 0.99 & 0.97 & 0.92 & 0.99 \\
\hline Rab & 0.99 & 0.99 & 0.99 & 0.98 & 0.94 & 0.99 \\
\hline Upper Thoracic & 0.97 & 0.90 & 0.99 & 0.98 & 0.94 & 0.99 \\
\hline \multicolumn{7}{|c|}{ Transverse plane } \\
\hline ISB & 0.97 & 0.92 & 0.99 & 0.93 & 0.81 & 0.98 \\
\hline Lower Thoracic & 0.99 & 0.96 & 0.99 & 0.90 & 0.66 & 0.97 \\
\hline Rab & 0.97 & 0.88 & 0.99 & 0.92 & 0.75 & 0.97 \\
\hline Upper Thoracic & 0.98 & 0.92 & 0.99 & 0.88 & 0.26 & 0.97 \\
\hline
\end{tabular}


Table 4. Intraclass correlation coefficients (ICCs) for absolute agreement, with $95 \%$ confident intervals for the flexion/extension peak, right/left lateral flexion peak and right/left rotation peak for the thorax angle and thorax angular velocity between the HubemaLab model and the different thorax models during walking.

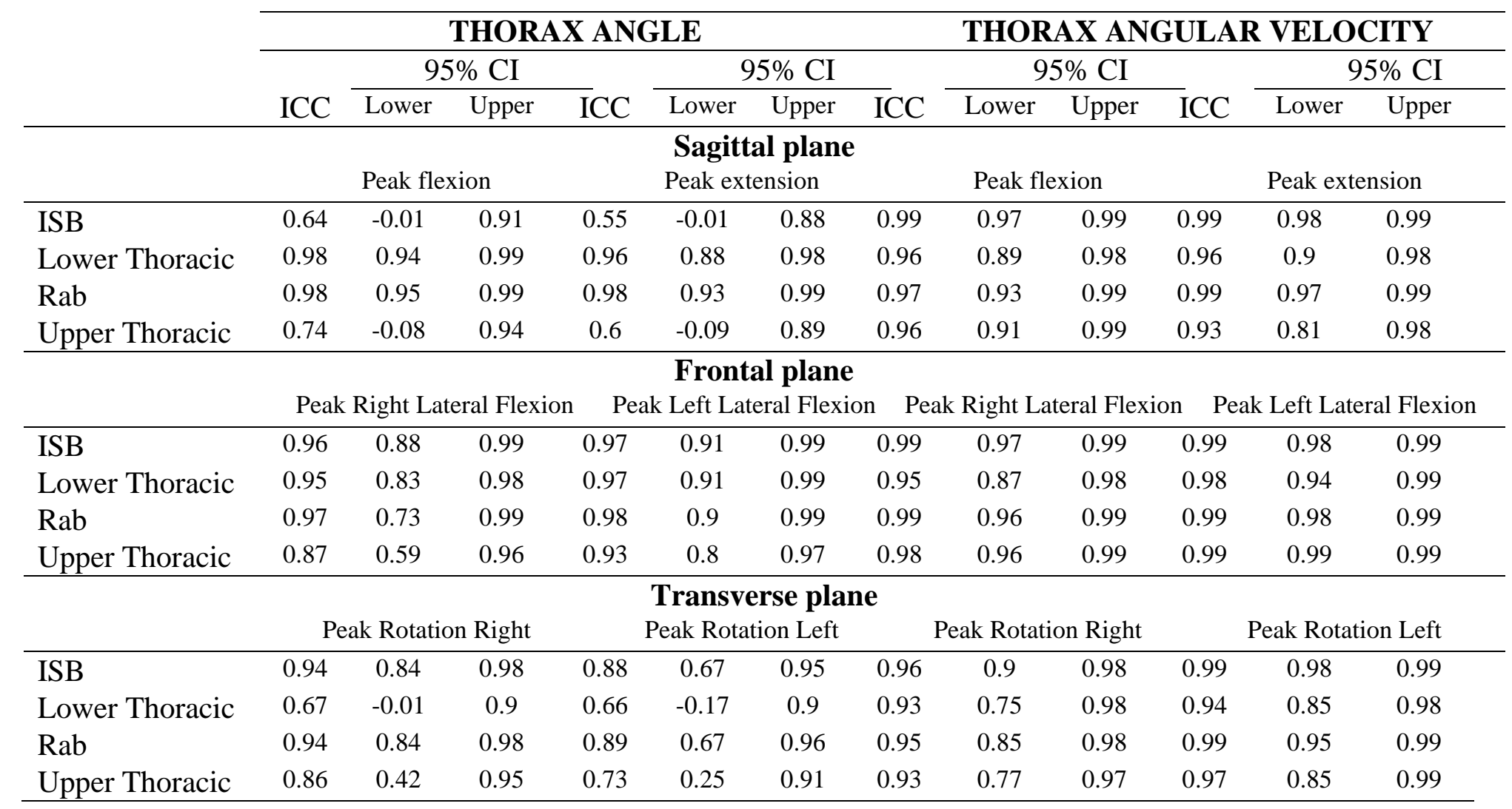




\section{FIGURES:}

Figure 1. Comparison of thorax kinematic waveforms obtained from the different marker set models analyzed (average for the group for each marker set model).
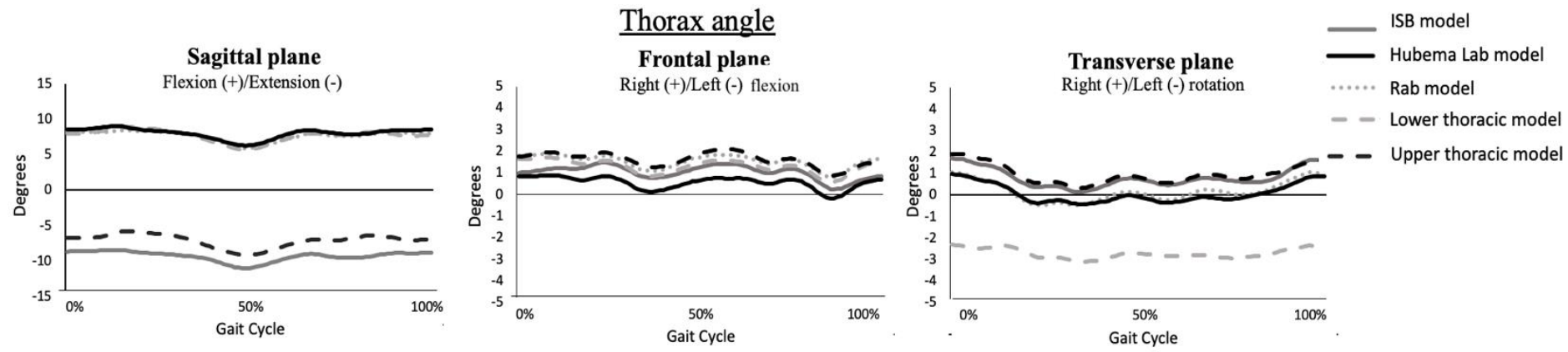

Thorax angular velocity
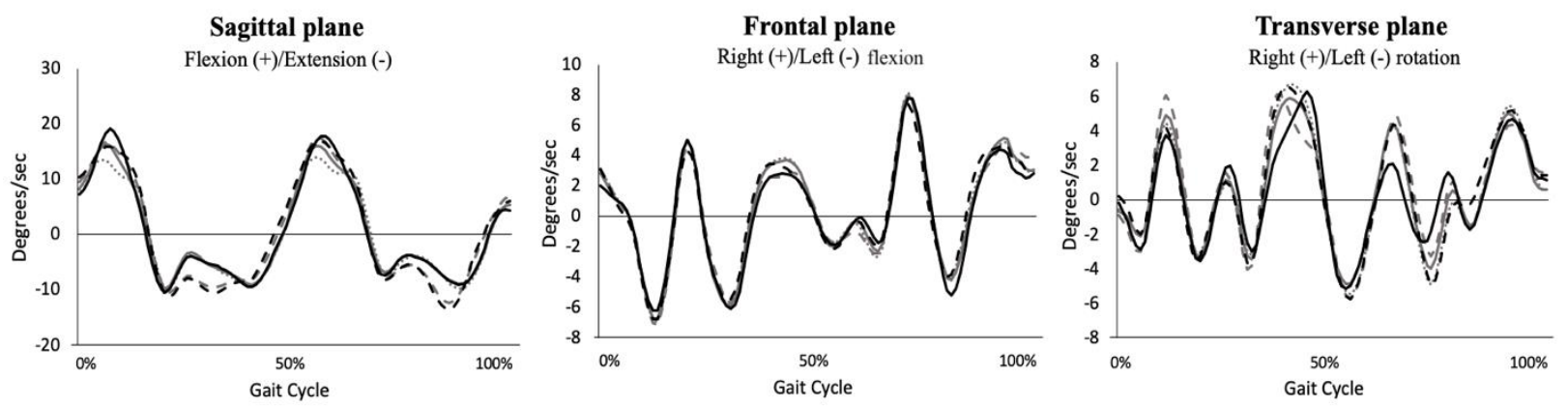

10. SUPPLEMENTARY MATERIAL LEGENDS:

Figure 2. Results of Bland-Altman test for thorax angle ROM data (degrees). 
Figure 3. Results of Bland-Altman test for the range of thorax angular velocity of (degrees/second).
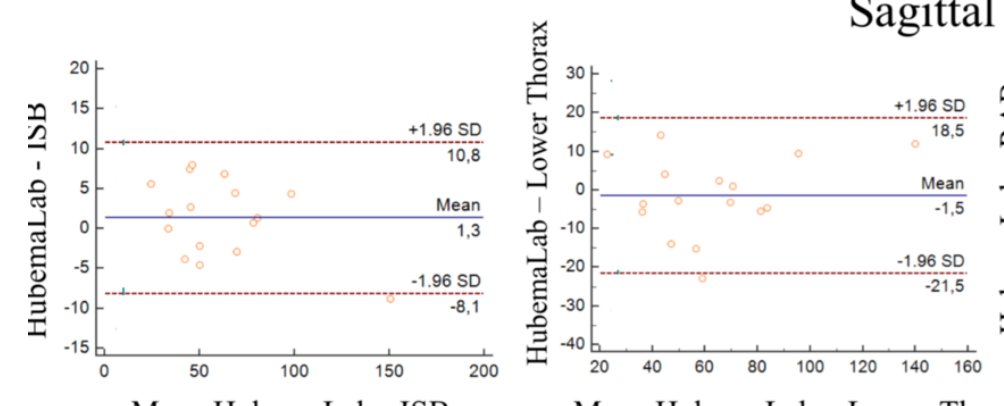

\section{$\underline{\text { RANGE OF ANGULAR VELOCITY }}$}

Mean HubemaLab - ISB

Mean HubemaLab - Lower Thorax
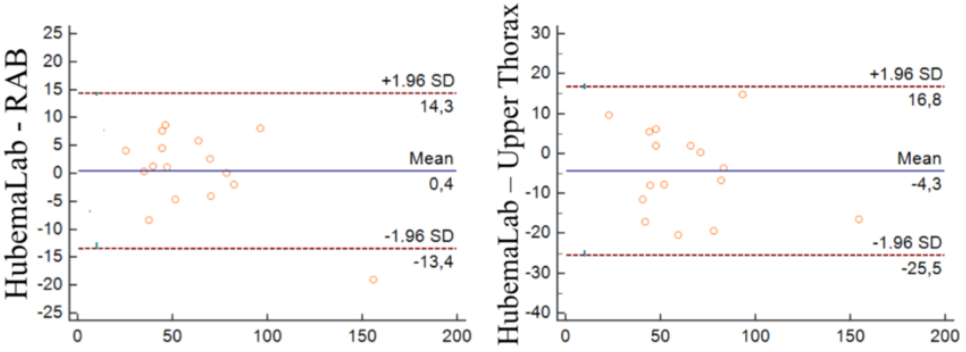

\section{Frontal Plane}
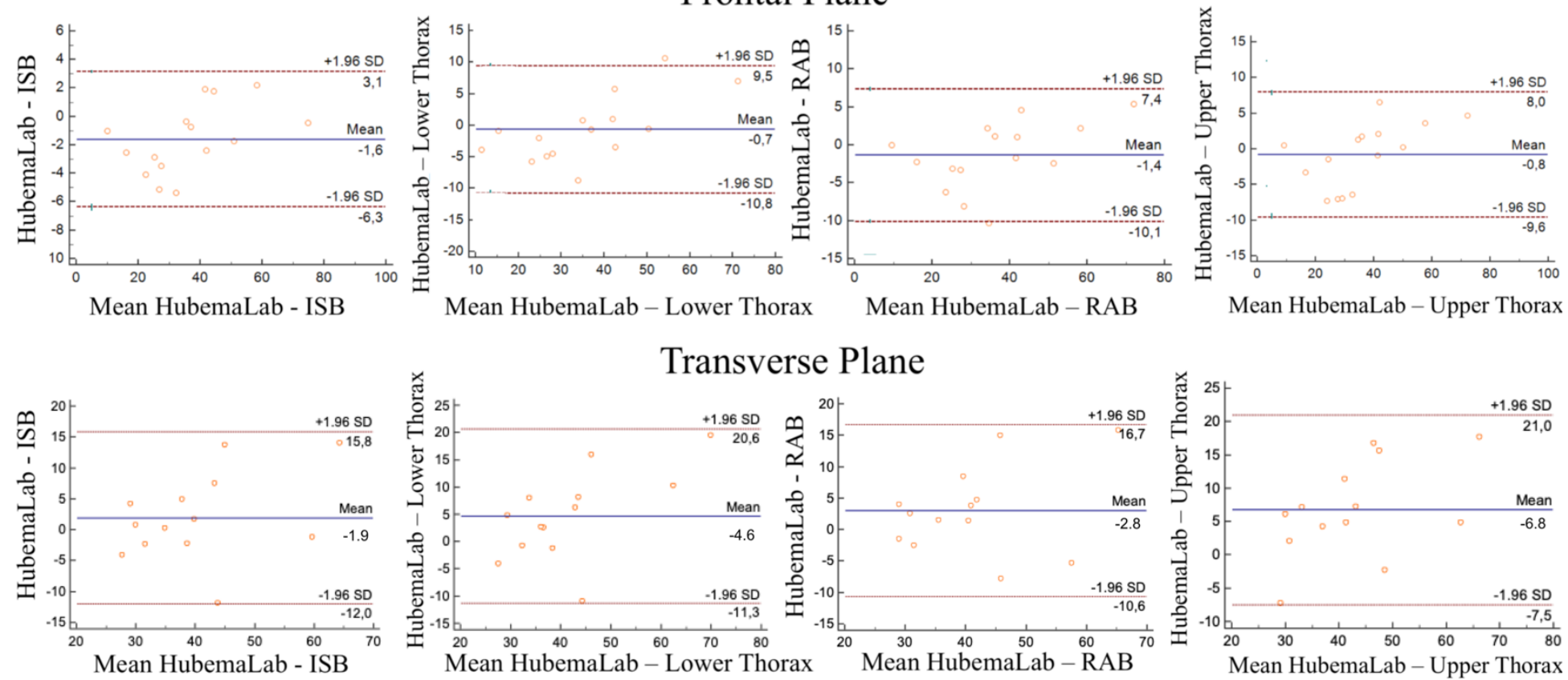